\title{
Structure and Function of N-Terminal Zinc Finger Domain of SARS-CoV-2 NSP2
}

\author{
Jun $\mathrm{Ma}^{1} \cdot$ Yiyun $\mathrm{Chen}^{2} \cdot$ Wei $\mathrm{Wu}^{1} \cdot$ Zhongzhou Chen $^{1}$ (])
}

Received: 14 June 2021 / Accepted: 15 July 2021 / Published online: 16 August 2021

(C) Wuhan Institute of Virology, CAS 2021

\begin{abstract}
SARS-CoV-2 has become a global pandemic threatening human health and safety. It is urgent to find effective therapeutic agents and targets with the continuous emergence of novel mutant strains. The knowledge of the molecular basis and pathogenesis of SARS-CoV-2 in host cells requires to be understood comprehensively. The unknown structure and function of nsp2 have hindered our understanding of its role in SARS-CoV-2 infection. Here, we report the crystal structure of the N-terminal of SARS-CoV-2 nsp2 to a high resolution of $1.96 \AA$. This novel structure contains three zinc fingers, belonging to the $\mathrm{C} 2 \mathrm{H} 2, \mathrm{C} 4$, and $\mathrm{C} 2 \mathrm{HC}$ types, respectively. Structure analysis suggests that nsp2 may be involved in binding nucleic acids and regulating intracellular signaling pathways. The binding to single or double-stranded nucleic acids was mainly through the large positively charged region on the surface of nsp2, and K111, K112, K113 were key residues. Our findings lay the foundation for a better understanding of the relationship between structure and function for nsp2. It is helpful to make full use of nsp2 as further research and development of antiviral targets and drug design.
\end{abstract}

Keywords Severe acute respiratory syndrome coronavirus 2 (SARS-CoV-2) - Crystal structure - Zinc finger · Electrophoretic mobility shift assays (EMSA) $\cdot$ Small-angle X-ray scattering (SAXS)

\section{Introduction}

Severe acute respiratory syndrome coronavirus 2 (SARSCoV-2), the etiological agent of COVID-19, has become a catastrophe to the entire mankind and society causing incalculable damage (Bai et al. 2020). Since its first outbreak in 2019, it has caused more than 188 million infections with over 4.06 million deaths until July 17, 2021, according to WHO (https://www.who.int/emergencies/dis eases/novel-coronavirus-2019), and those numbers are still rising (Yip et al. 2020). As a global pandemic, SARS-CoV-2

Supplementary Information The online version contains supplementary material available at https://doi.org/10.1007/s12250021-00431-6.

Zhongzhou Chen

chenzhongzhou@cau.edu.cn

1 State Key Laboratory of Agrobiotechnology and Beijing Advanced Innovation Center for Food Nutrition and Human Health, College of Biological Sciences, China Agricultural University, Beijing 100193, China

2 Cherry Creek High School, 9300 East Union Avenue, Greenwood Village 80111, USA has become the focus of researchers. Efforts are being made to find effective drugs and therapeutics to control the spread of SARS-CoV-2 as much as possible.

As a member of the Nidovirales order in the Coronaviridae family, SARS-CoV-2 is one of the largest positive-stranded RNA viruses with an approximately $30 \mathrm{~kb}$ genome in length with a $5^{\prime}$ cap and a $3^{\prime}$ poly A tail (Wang et al. 2020; Clark et al. 2021). The ORF1a and ORF1ab locate in the $5^{\prime}$ terminal viral genomes coding for polyproteins, including pp1a and pplab by ribosome shifting, and then the proteases hydrolyze and cleave polyproteins into 16 distinct nonstructural proteins (nsps) (Al-Qaaneh et al. 2021). The nsps that participate in viral genome replication and transcription are essential for the survival of the SARS-CoV-2. The nsps related to viral pathogenesis would stimulate effective immune responses, which were potential vaccine candidates (Ong et al. 2020). For example, $142 \mathrm{~T}$ cell epitopes were mapped across the SARS-CoV-2 genome, and 6 from the nsp2 (Mateus et al. 2020).

The unknown structure and function of nsp2 have hindered our understanding of its role in SARS-CoV-2 infection. The study of viral-host protein interaction found 
that SARS-CoV nsp2 could interact with host proteins widely including prohibitin 1 (PHB1) and PHB2, which were implicated in a number of cellular functions, including cellular migration, differentiation, apoptosis, and so on (von Brunn et al. 2007; Cornillez-Ty et al. 2009; Justo Arevalo et al. 2021). Deletions of the nsp2 in MHV and SARS-CoV resulted in attenuating of viral growth and RNA synthesis, but not death (Graham et al. 2005). Although nsp2 exists in SARS-CoV, SARS-CoV-2, and Middle East respiratory syndrome coronavirus (MERS$\mathrm{CoV}$ ), there are relatively large sequence differences among three coronavirus pathogens that have posed great threats to human health (Singh et al. 2020). Sequence alignment found that the identity of nsp2 between SARSCoV-2 and SARS-CoV was 76.8\%, while between SARSCoV-2 and MERS-CoV was $24.2 \%$ (Supplementary Fig. S1). Mutation and evolutionary analysis of SARSCoV-2 revealed that nsp2 Thr85Ile reached a high frequency in North America (>60\%) in March 2020. But no structural information is available to determine the specific function of this site (Zhao et al. 2020). What role nsp2 plays in the process of SARS-CoV-2 infection remains to be explored. The acquisition of high-resolution structures is an effective and critical method in understanding the function of SARS-CoV-2 nsp2.

Here, we report the high-resolution crystal structure of the N-terminal of SARS-CoV-2 nsp2 with a resolution of $1.96 \AA$. The structure consists of three zinc fingers $(\mathrm{ZnFs})$. The large area of positive charge on the surface and experiments reveal the ability of binding with nucleic acids. Residues K111, K112, and K113 are key sites for binding nucleic acids. Combined with the structure, the epitopes might be mapped better to understand the immune responses to SARS-CoV2 and possible implications for vaccines.

\section{Materials and Methods}

\section{Protein Expression}

The full-length gene SARS-CoV-2 nsp2 (nsp2 full-length $_{\text {) of }}$ 638 amino acid residues was obtained from Prof. Bo Zhang (Wuhan Institute of Virology, Chinese Academy of Sci-

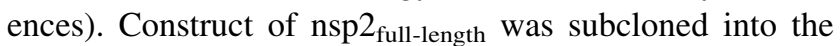
EcoR I/Kpn I sites of a modified pPICZ expression vector with a C-terminal GFP- $6 \times$ His tag under the AOX1 promoter for eukaryotic expression. The plasmids were transformed into $P$. pastoris $\mathrm{X}-33$ cells. The expression was detected by GFP fluorescence in a small scale. After screening the strains with high expression, they were cultured in $\mathrm{BMM}$ medium $(100 \mathrm{mmol} / \mathrm{L}$ potassium phosphate
$\mathrm{pH} 6.0,1.34 \% \mathrm{YNB}, 1 \%$ methanol) at $28{ }^{\circ} \mathrm{C}$ for $72 \mathrm{~h}$, and methanol was added every $24 \mathrm{~h}$.

Using nsp $2_{\text {full-length }}$ as a template, the N-terminal of 276 amino acid residues (nsp2 1-276) was inserted into pGEX expression vector (Novagen). The mutant of $n s p 2_{1-276}$ was created using site-directed mutagenesis and verified by DNA sequencing. The GST fusion tags are cut from the nsp2 $2_{1-276}$ constructs by a tobacco etch virus (TEV) protease cleavage site. The plasmids were transformed into Escherichia coli BL21 (DE3) cells. Cells were incubated in Luria-Bertani medium at $37{ }^{\circ} \mathrm{C}$ until the $\mathrm{OD}_{600}$ reached $0.8-1.0$ and then supplemented with $100 \mu \mathrm{mol} / \mathrm{L} \mathrm{ZnCl}_{2}$, meanwhile induced with $0.2 \mathrm{mmol} / \mathrm{L}$ isopropyl-D-thiogalactoside for an additional $12 \mathrm{~h}$ at $18{ }^{\circ} \mathrm{C}$.

\section{Protein Purification}

Both yeast and $E$. coli cultures were harvested by centrifugation at $4,000 \times g$ for $10 \mathrm{~min}$ at $4{ }^{\circ} \mathrm{C}$, and resuspended in a lysis buffer $(20 \mathrm{mmol} / \mathrm{L}$ Tris $\mathrm{pH} 7.5$, $500 \mathrm{mmol} / \mathrm{L} \mathrm{NaCl}, 2 \mathrm{mmol} / \mathrm{L} \quad \beta$-mercaptoethanol, $5 \%$ glycerol, $30 \mathrm{mmol} / \mathrm{L}$ imidazole), then added with $0.1 \%(\mathrm{v} / \mathrm{v})$ Triton X-100 and $1 \mathrm{mmol} / \mathrm{L}$ PMSF (Invitrogen). Cells were disrupted by high pressure $(1,800 \mathrm{bar}, P$. pastoris $)$ or sonication $(E$. coli), then clarified by centrifugation at $18,300 \times g$ for $45 \mathrm{~min}$ to remove cell debris. The supernatant was applied to a $\mathrm{Ni}^{2+}$-chelating column or GST affinity column (GE Healthcare). The GFP or GST fusion tag of the proteins was cleaved using TEV protease at $4{ }^{\circ} \mathrm{C}$ for 6-8 h. The protein sample was then loaded onto a Q Sepharose (GE Healthcare), and eluted with a $\mathrm{NaCl}$ gradient. The proteins were further purified by size exclusion chromatography using Superdex 200 10/300, (GE Healthcare) in SEC buffer ( $20 \mathrm{mmol} / \mathrm{L}$ Tris $\mathrm{pH} 7.5$, $150 \mathrm{mmol} / \mathrm{L} \mathrm{NaCl}, 2 \mathrm{mmol} / \mathrm{L}$ TCEP). The peak fractions were collected and checked by SDS-PAGE (Fig. 1A). The protein with a purity of $95 \%$ was concentrated to $5.5 \mathrm{mg} /$ $\mathrm{mL}$ and stored at $4{ }^{\circ} \mathrm{C}$ for further use.

\section{Crystallization and Data Collection}

Initial crystal screening was performed at $4{ }^{\circ} \mathrm{C}$ with multiple commercial screens (Hampton Research). Using the sitting-drop vapor diffusion method, $1 \mu \mathrm{L}$ of purified protein was mixed with $1 \mu \mathrm{L}$ reservoir solution in 48-well plates. Initial nsp2 $2_{1-276}$ crystals were grown in a reservoir solution containing 20\% PEG 8000, $0.1 \mathrm{~mol} / \mathrm{L}$ HEPES $\mathrm{pH}$ 7.0 at $4{ }^{\circ} \mathrm{C}$. Unfortunately, the crystal of nsp $2_{\text {full-length }}$ was not obtained after many attempts. Crystals of nsp2 ${ }_{1-276}$ were further refined by the hanging-drop vapor diffusion method, and the protein was mixed with reservoir solution in different volume ratios. 
Fig. 1 The overall structure of nsp2. A. The nsp2 ${ }_{1-276}$, nsp2 $2_{\text {full-length }}$, and nsp2 $2_{1-276}$ mutant1 (K111A/K112A/ K113A) samples after size exclusion chromatography purification, respectively. B The overall structure of nsp2 $2_{1-276}$ consists of four chains in the asymmetric unit. A, B, C, D four chains are shown in pink, yellow-orange, cyan, and green, respectively. $\mathbf{C}$ The stereo structure of nsp2 $2_{1-276}$. The $\alpha$-helices and $\beta$-sheets are colored cyan and magenta, respectively, and the three zinc atoms are shown as red, blue, and yellow spheres,

respectively. The diagram of $\mathrm{Zn}^{2+}$ binding site is illustrated under the stereo structure of nsp2 $1_{1-276}$.

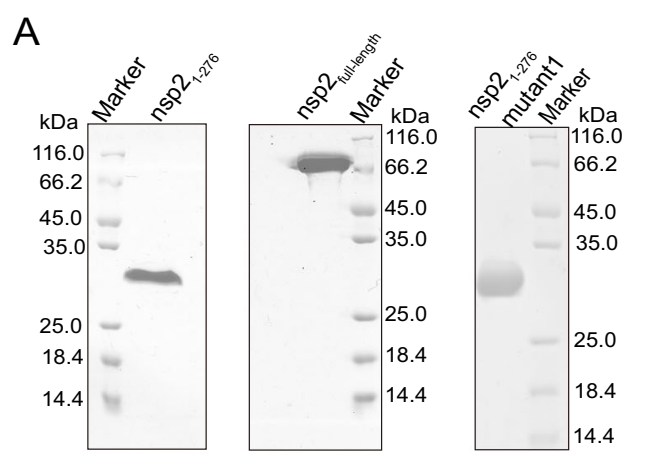

B

C

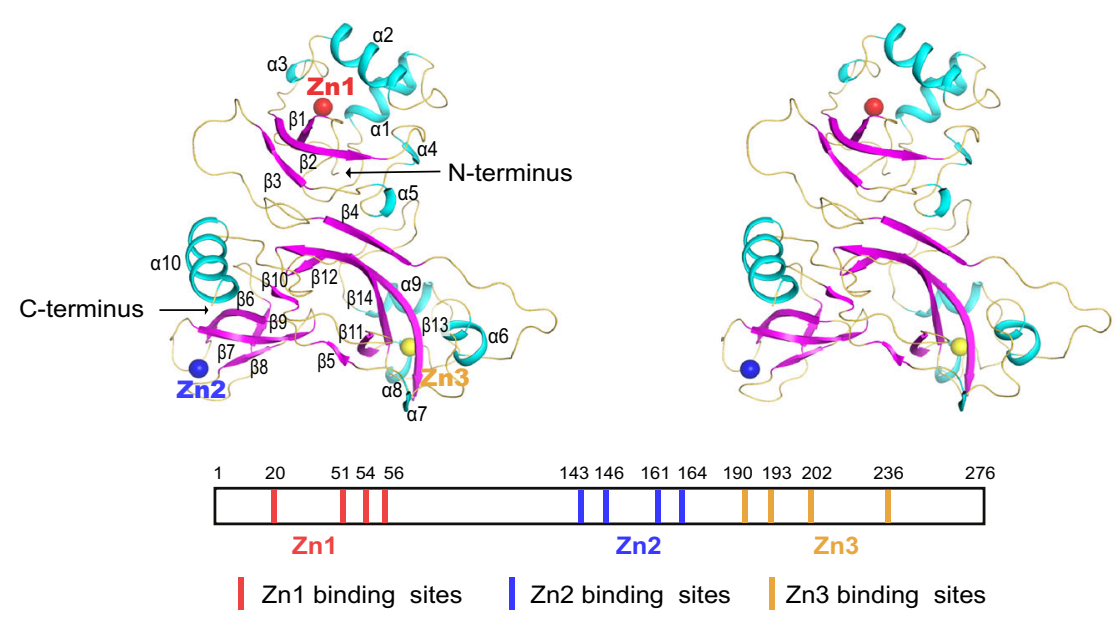

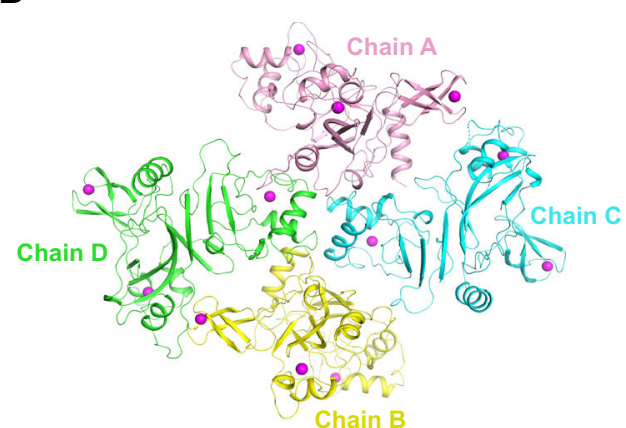
(n)

The structure was refined finally to $1.96 \AA$ resolution with an $\mathrm{R}_{\text {work }}$ of $19.97 \%$ and an $\mathrm{R}_{\text {free }}$ of $22.56 \%$.

After precipitant concentration and $\mathrm{pH}$ optimized, welldiffracted crystals were finally obtained in $18 \%$ PEG 8000 , $0.1 \mathrm{~mol} / \mathrm{L}$ HEPES pH 7.5 at a 2.5:2 (v/v, protein/reservoir solution) at $4{ }^{\circ} \mathrm{C}$ (Supplementary Fig. S2A, S2B). The crystals were flash-cooled in liquid nitrogen in mother liquor containing $20 \%$ glycerol as a cryoprotectant. Data were collected on beamlines BL17U1 at Shanghai Synchrotron Radiation Facility (SSRF). Data were indexed, integrated, and scaled by autoPROC and XDS (Yu et al. 2019). The statistics are summarized in Table 1.

\section{Structural Determination}

The structure of nsp2 $2_{1-276}$ was solved by the single-wavelength anomalous diffraction (SAD) method. The anomalous signals in the data were strong as analyzed by SHELX C program (Sheldrick 2008), indicating the existence of zinc atoms. There initial $\mathrm{Zn}$ sites were found by the program SHELX D with a $\mathrm{CC}_{\text {weak }} / \mathrm{CC}_{\text {all }}$ of $20.8 / 28.9$ in space group $P 2{ }_{1}$. Twelve initial $\mathrm{Zn}$ sites were found and the phases were generated. The crude partial model with $19 \beta$ sheets and $27 \alpha$-helices in 787 residues was built by program SHELEX $\mathrm{E}$ and figure of merit reached 0.626 (Sheldrick 2008). The initial model was further adjusted by manual model building using COOT (Emsley et al. 2010) and refinement using REFMAC5 (Murshudov et al. 2011).

\section{SAXS Experiments}

Small-angle X-ray scattering (SAXS) data were performed at the beamline BL19U2 of the SSRF. Briefly, proteins were subjected to size exclusion chromatography with buffer $(20 \mathrm{mmol} / \mathrm{L}$ HEPES $\mathrm{pH} 7.5,150 \mathrm{mmol} / \mathrm{L} \mathrm{NaCl})$. Various concentrations of protein samples were tested, and the data were collected at $1.03 \AA$ with 20 frames and a distance of $1 \mathrm{~m}$ from the detector. Individual data were used to process by using Software RAW (Nielsen et al. 2009). The scattering data from the buffer alone were measured before and after each sample, and the average of the scattering data before and after each sample was used for background subtraction. The scattering data and the structure PDB file for fitting were submitted to the FoXS online server (http://modbase.compbio.ucsf.edu/foxs/) (Pelikan et al. 2009).

\section{Electrophoretic Mobility Shift Assays (EMSA)}

Single or double-stranded DNAs (ssDNA or dsDNA) were used for EMSA. The ssDNA sequence is: 5'-GATGTGATTTTAATAGCTTCTTAGGAGAATGACAAAAAA 
Table 1 Data collection and refinement statistics of SARS-CoV-2 nsp2 ${ }_{1-276}$ (PDB: 7EXM)

\begin{tabular}{|c|c|}
\hline Parameters & Value \\
\hline \multicolumn{2}{|l|}{ Data collection } \\
\hline Wavelength $(\AA)$ & 0.9793 \\
\hline Space group & $P 2_{1}$ \\
\hline \multicolumn{2}{|l|}{ Cell dimensions } \\
\hline a,b,c $(\AA)$ & $57.93,159.6,63.55$ \\
\hline$\alpha, \beta, \gamma\left(^{\circ}\right)$ & $90,91.2,90$ \\
\hline Resolution $(\AA)^{\mathrm{a}}$ & $50.0-1.96(2.06-1.96)$ \\
\hline$I / \sigma$ & $17.9(2.7)$ \\
\hline Rmerge & $0.062(0.673)$ \\
\hline Completeness (\%) & $99.8(99.7)$ \\
\hline Total No. of reflections & 555,159 \\
\hline Unique reflections & 82,763 \\
\hline Redundancy & $6.7(5.8)$ \\
\hline \multicolumn{2}{|l|}{ Refinement } \\
\hline Resolution $(\AA)$ & $50.0-1.96$ \\
\hline No. of reflections & 75,133 \\
\hline$R_{\text {work }} / R_{\text {free }}(\%)$ & $19.97 / 22.56$ \\
\hline \multicolumn{2}{|l|}{ No. of atoms } \\
\hline Protein & 8406 \\
\hline Ligand/ion & 18 \\
\hline Water & 925 \\
\hline \multicolumn{2}{|l|}{$B$-factors $\left(\AA^{2}\right)$} \\
\hline Protein & 34.26 \\
\hline Ligand/ion & 39.12 \\
\hline Water & 42.08 \\
\hline \multicolumn{2}{|l|}{ r.m.s. deviations ${ }^{\mathrm{b}}$} \\
\hline Bond lengths $(\AA)$ & 0.003 \\
\hline Bond angles $\left({ }^{\circ}\right)$ & 1.29 \\
\hline Ramachandran Plot $(\%)^{\mathrm{c}}$ & $96.8 / 3.2 / 0.0$ \\
\hline
\end{tabular}

${ }^{\text {a }}$ Statistics for highest resolution shell.

${ }^{\mathrm{b}}$ Root mean square deviations

${ }^{\mathrm{c}}$ Residues in favored, allowed, and outlier regions of the Ramachandran plot.

AAAAAAAAAAAAAAAAAAAAAAAAAA-3', which is similar to the 3'-UTR RNA sequence of SARS-COV-2. Double-stranded DNAs were prepared by annealing two oligonucleotides (the above ssDNA and its complementary DNA) slowly. In short, the mixture of the two complementary oligos was incubated at $95{ }^{\circ} \mathrm{C}$ for $5 \mathrm{~min}$ and then annealed two degrees per minute to $4{ }^{\circ} \mathrm{C}$. Different amounts of full length and nsp2 $2_{1-276}$ were incubated with $5 \mu \mathrm{mol} / \mathrm{L}$ ssDNA or dsDNA in a $20 \mu \mathrm{L}$ reaction volume for $2 \mathrm{~h}$ at $25{ }^{\circ} \mathrm{C}$ and the mixture was then separated on a $6 \%$ native polyacrylamide gel in $1 \times \mathrm{TG}$ buffer $(45 \mathrm{mmol} / \mathrm{L}$ Tris $\mathrm{pH}$ 8.0, $45 \mathrm{mmol} / \mathrm{L}$ glycine $\mathrm{pH} 8.9)$ and $1 \times \mathrm{TB}$ buffer $(45 \mathrm{mmol} / \mathrm{L}$ Tris $\mathrm{pH} 8.0,45 \mathrm{mmol} / \mathrm{L}$ boric acid, $\mathrm{pH}$
8.0) at $180 \mathrm{~V}$ for about $45 \mathrm{~min}$, respectively. The incubation molar ratios of full length and nsp2 ${ }_{1-276}$ to nucleic acid were shown in the figures. In order to investigate whether the zinc finger structures were involved in interacting nucleic acid, the zinc ions of nsp2 $2_{1-276}$ were chelated with gradient EDTA concentration $(0-200 \mathrm{mmol} / \mathrm{L})$. The nsp2 $2_{1-276}$ mutant 1 (K111A/K112A/K113A) was incubated with DNA at a 15:1 molar ratio to study the effect of residues K111, K112, and K113 on binding nucleic acids. The DNAs were visualized by staining with GelRed.

\section{Results}

\section{The Overall Structure of nsp2 N-Terminus Reveals a Novel Zinc Finger Domain}

Since the full-length nsp2 didn't get crystals eventually, we tried to express a series of truncated nsp2 proteins. After many attempts, only one fragment of nsp2 (residues 1-276) was finally obtained crystals. After crystal screening and optimization, well-diffracted crystals were acquired at $4{ }^{\circ} \mathrm{C}$ (Supplementary Fig. S2). The expressions of nsp2 $2_{1-276}$ and $n s p 2_{\text {full-length }}$ proteins are shown in Fig. $1 \mathrm{~A}$. By SAD method and manual model building in COOT combined with refinement in REFMAC5, the final nsp2 ${ }_{1-276}$ structure in the space group $P 2{ }_{1}$ was refined to $1.96 \AA$ resolution with an $\mathrm{R}_{\mathrm{work}}$ of $19.97 \%$ and an $\mathrm{R}_{\text {free }}$ of $22.56 \%$ (Table 1 ).

The structure of nsp2 $2_{1-276}$ consists of four chains in the asymmetric unit and the overall conformation looks like a four-leaf clover (Fig. 1B). Chain A is symmetric to chain $\mathrm{B}$, and chain $\mathrm{C}$ is symmetric to chain $\mathrm{D}$. Each chain contains ten $\alpha$-helices $(\alpha 1-\alpha 10)$ and fourteen $\beta$-sheets $(\beta 1-$ $\beta 14$ ) with three $\mathrm{ZnFs}$ to form a complete domain (Fig. 1C). Each chain binds three zinc atoms, arranged in symmetrical triangles.

The side chains of Cys20 in $\alpha 1$, Cys51, His54, and His56 in the loop coordinate the zinc ion $\mathrm{Zn} 1$ within a stable fold to form the classical $\mathrm{C} 2 \mathrm{H} 2$ zinc finger structure (ZnF1) (Eom et al. 2016) (Fig. 2A). The $\mathrm{ZnF} 2$ coordinated by the Cys143, Cys146, Cys161, and Cys165 belongs to a $\mathrm{C} 4$ type zinc finger, and four reversed $\beta$-sheets form a clamped structure with zinc ions $\mathrm{Zn} 2$ nested inside (Fig. 2B). $\mathrm{Zn} 3$ ion is tetrahedrally coordinated by three cysteines (C190, C193, C236) in $\beta 11, \alpha 8$, and $\beta 13$ respectively, and one histidine $\mathrm{H} 202$ in loop to form a C2HC type $\mathrm{ZnF}$ (Fig. 2C, 2D).

\section{The Oligomeric State of $n s p 2_{1-276}$ in Solution}

It is worth exploring whether the oligomeric state of $n s p 2_{1-276}$ in solution is monomer or tetramer since the overall structure consists of four chains. We have 
Fig. 2 Close-up view of three zinc finger structures. A The first $\mathrm{Zn} 1$ ion (red) is engaged by residues $\mathrm{C} 20, \mathrm{C} 51, \mathrm{H} 54$, and H56. B The second $\mathrm{Zn} 2$ ion (blue) is engaged by residues C143, C146, C161, and C164. C The third $\mathrm{Zn} 3$ ion (yellow) is engaged by residues C190, C193, H202, and C236. All the residues are the same color $(\mathrm{C}$, orange; N, blue; S, yellow; O, red). D The topology of these three zinc fingers. Blue cylinders and red arrows represent helices and $\beta$-sheets, respectively.
A

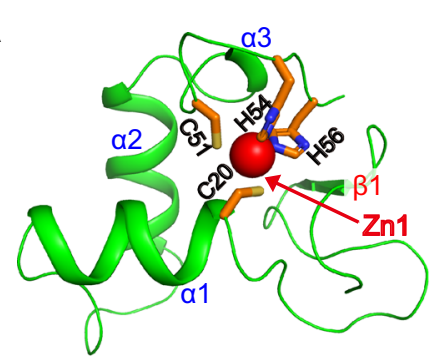

C

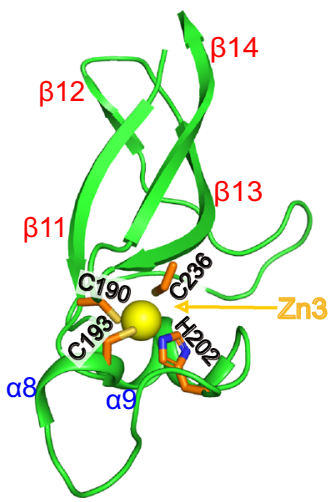

B

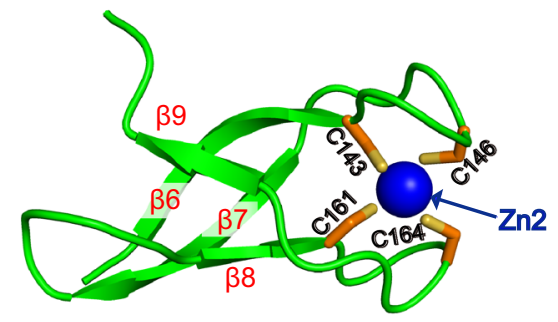

D

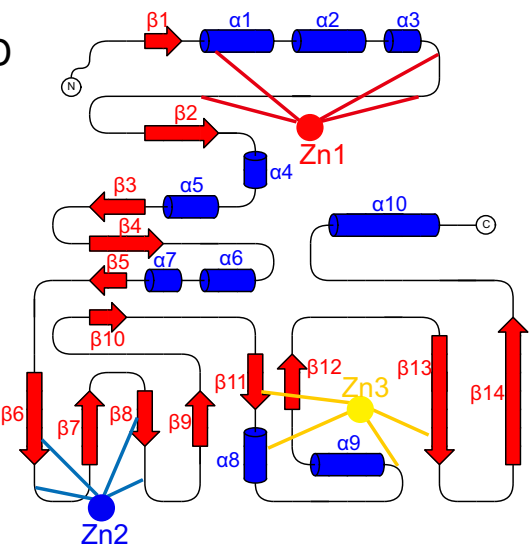

performed gel filtration analyses and SAXS experiments to analyze the oligomeric states of nsp2 $2_{1-276}$ in solution. The single peak in the size exclusion chromatography suggests that it is a monomer in solution (Fig. 3A). Furthermore, SAXS results also indicated that monomer fitted best in solution, while tetramer fitted worse (Fig. 3B, 3C). SAXS data and analysis are listed in Supplementary Table S1. Therefore, four $\mathrm{nsp} 2_{1-276}$ solved in the asymmetric unit were not analyzed because it was formed by crystal packing.

\section{K111, K112, and K113 Are Key Residues for Binding Nucleic Acids}

Numerous studies have reported that $\mathrm{ZnF}$ containing proteins are generally involved in protein-protein, proteinDNA, and protein-RNA interactions (Eom et al. 2016; Sulej 2019). To the best of our knowledge, the biochemical function of nsp2 is unknown. To uncover it, we performed structural analysis. There is a large positively charged region on the electrostatic surface of nsp2 (Fig. 4A). Thus, we hypothesized that the positively charged region on the
Fig. 3 The oligomeric analyses of nsp2 $2_{1-276}$ in solution. A Size exclusion chromatography of nsp2 $2_{1-276}$ on a Superdex 200 10/300 GL column (GE Healthcare). The theoretical scattering curves of monomer $(\mathbf{B}$, red) and tetramer $(\mathbf{C}$, yellow) are shown. Experimental data are represented by blue dots. D Pair distance distribution $P(r)$ of nsp2 $2_{1-276}$.
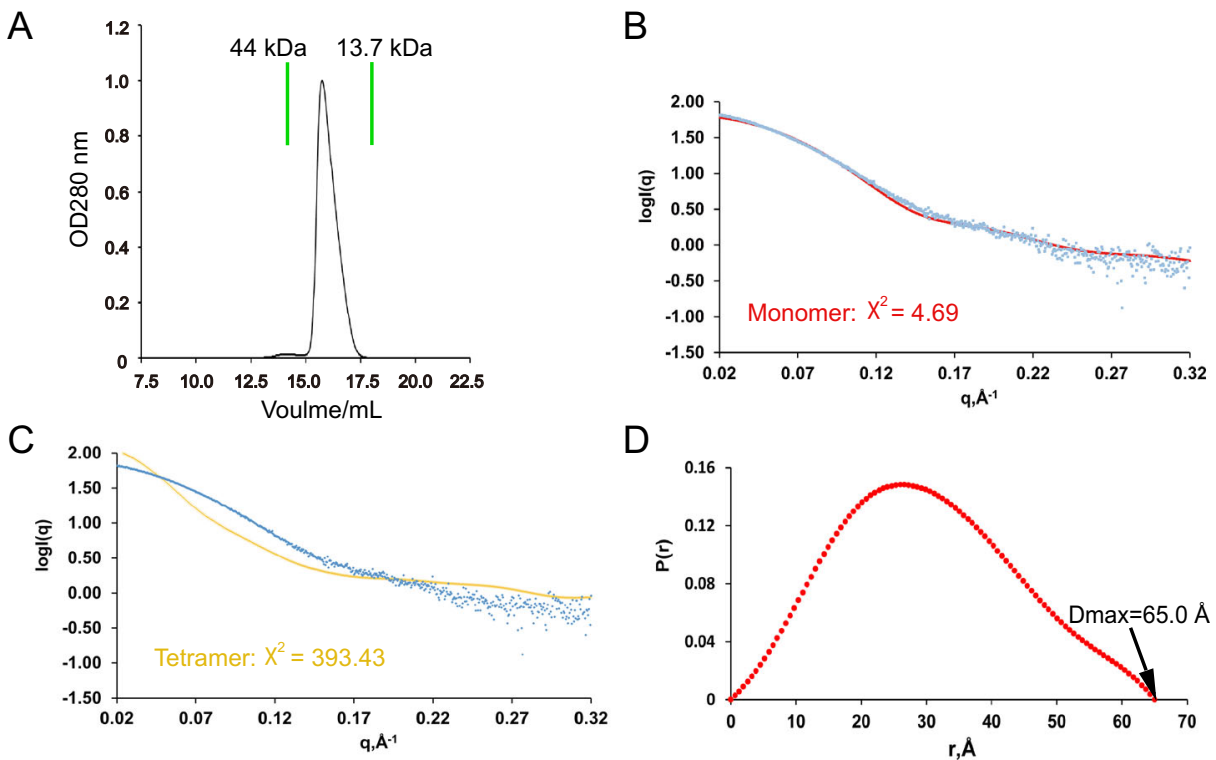


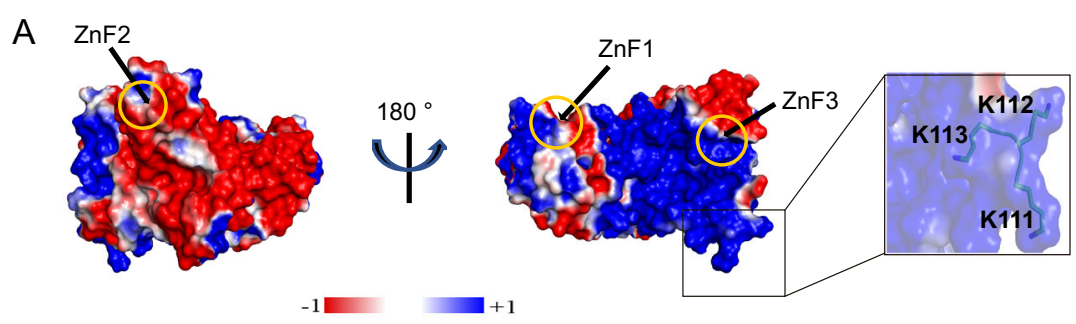

B

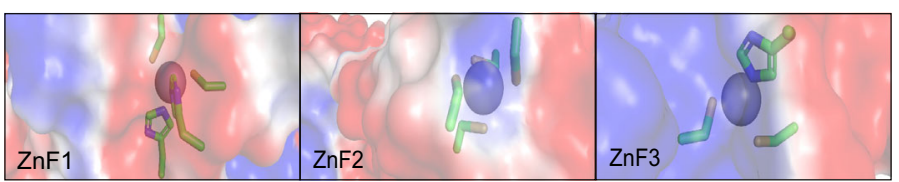

Fig. 4 Nsp2 has a large positive surface. A The electrostatic surface of nsp2 (red, negatively charged; white, non-polar; blue, positively charged). Residues K111, K112, and K113 are shown particularly. B Emphasized charged details of three zinc finger structures $(\mathrm{ZnF} 1$,

surface of nsp2 was involved in binding nucleic acids. Since nsp2 may not only participate in the viral replication and transcription, but also affect the host genome to inhibit the synthesis of host protein. We speculated that nsp2 might interact with ssDNA or dsDNA. EMSA assay showed that both full-length and nsp2 $2_{1-276}$ could bind ssDNA or dsDNA, and the higher the protein concentration, the more obvious the complex band was (Fig. 5A5D). Interestingly, $\mathrm{ZnF} 1, \mathrm{ZnF} 2$, and $\mathrm{ZnF} 3$ are not the most positively charged regions (Fig. 4B). Thus we used different concentrations of EDTA (0-200 mmol/L) to chelate $\mathrm{Zn}^{2+}$ ions to destroy the $\mathrm{ZnF}$ structures, and found that $200 \mathrm{mmol} / \mathrm{L}$ EDTA still could not affect the interaction of protein and DNA (Fig. 5E). The result shows that the three zinc fingers are not involved in binding nucleic acids directly. Meanwhile, we find three positively charged lysines (K111/K112/K113) located in a prominent position (Fig. 4A). No complex bands were observed when three successive positively charged lysine (K111/K112/K113) were mutated into uncharged alanine (Fig. 5F). Therefore, we can conclude that the interaction of nsp2 and nucleic acid depends on the large region of the positively charged surface, and residues K111, K112, and K113 are key sites.

\section{Discussion}

The continued spread of SARS-CoV-2 has presented a global health challenge confronting the entire international community. Coupled with rapid mutation, it has been a serious threat to human life and health (Shu et al. 2020). In addition to the development and promotion of vaccines, a better understanding of how SARS-CoV-2 reproduces and the discovery of potential antiviral targets are urgently needed. Non-structural proteins, as important targets for
$\mathrm{ZnF}$ 2, and $\mathrm{ZnF} 3$ ) by the electrostatic surface. Residues involved in binding $\mathrm{Zn}^{2+}$ are shown as stick models $(\mathrm{C}$, orange; $\mathrm{N}$, blue; $\mathrm{S}$, yellow; O, red).

drug development, play key roles in the replication and transcription of the virus. Nevertheless, the unknown structure and function of nsp2 impeded our understanding of SARS-CoV-2.

Although we have obtained full-length proteins with high purity, it is regrettable that we have not obtained crystals through a large number of crystallization tests (Fig. 1A). Here we present the first high-resolution crystal structure of $n s p 2_{1-276}$ at $1.96 \AA$ resolution. The overall structure has four protein molecules in an asymmetric unit (Fig. 1B). Interestingly, the gel filtration analyses and SAXS experiment indicated that the oligomeric state of nsp2 ${ }_{1-276}$ is monomeric in solution (Fig. 3). The superposition of the four chains reveals some slight differences at the ends with a root mean squared deviation (RMSD) of $\sim 1.0 \AA$ between each chains (Supplementary Fig. S3). This is mainly due to conformational flexibility in solution.

There is a large positively charged region on the surface (Fig. 4A). Structural analysis and EMSA results confirmed that $n s p 2_{\text {full-length }}$ and $n s p 2_{1-276}$ could bind to ssDNA or dsDNA (Fig. 5A-5D) and high concentrations of EDTA could not destroy this interaction (Fig. 5E). Furthermore, we found three positively charged lysines located in a prominent position (Fig. 4A). Mutation of lysine to alanine completely lost their ability to interact with nucleic acids (Fig. 5F). These results indicate that the interaction of nsp2 and nucleic acid is mainly dependent on the positively charged region on the surface, and K111, K112, K113 are key residues. However, the binding affinity of nsp2 to ssDNA or dsDNA was not high in our experiments. Other substrate RNA, the addition of other SARS-COV-2 or host proteins might improve the binding, and needs further study to confirm.

When we were submitting our manuscript, another group released two Cryo-EM structures (PDB:7MSW and 
Fig. 5 The binding of nsp2 to DNA. $5 \mu \mathrm{mol} / \mathrm{L} 65 \mathrm{nt}$ ssDNA binds to nsp2 $2_{\text {full-length }}(\mathbf{A})$ and nsp2 $2_{1-276}$ (B) with different concentrations $(25,50,100$, and $150 \mu \mathrm{mol} / \mathrm{L}$ ). Positions of free DNA and protein-bound DNA are indicated by red and blue arrows, respectively. $5 \mu \mathrm{mol} / \mathrm{L}$ 65 bp dsDNA binds to $\mathrm{nsp} 2_{\text {full-length }}(\mathbf{C})$ and nsp2 $2_{1-276}$ (D) with different concentration $(15,25,50,75$, and $100 \mu \mathrm{mol} / \mathrm{L})$. E $5 \mu \mathrm{mol} / \mathrm{L} 65 \mathrm{bp}$ dsDNA binds to $15 \mu \mathrm{mol} / \mathrm{L}$ nsp2 $2_{1-276}$ in the presence of different concentration of EDTA $(5,10,20,50,100,150$, $200 \mathrm{mmol} / \mathrm{L})$. F $5 \mu \mathrm{mol} / \mathrm{L}$ 65 bp dsDNA binds to $75 \mu \mathrm{mol} / \mathrm{L}$ nsp2 $1-276$ wild type (WT) and $75 \mu \mathrm{mol} / \mathrm{L} \mathrm{nsp2} 2_{1-276}$ mutant 1 (K111A/K112A/ K113A), respectively.
A

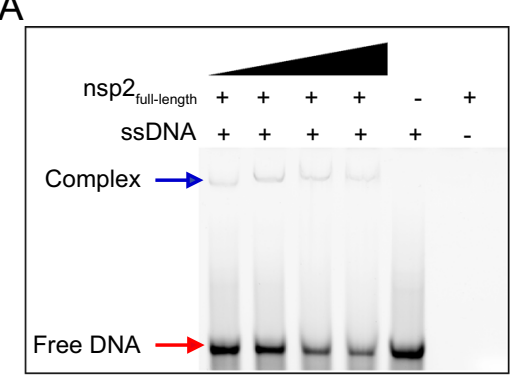

B

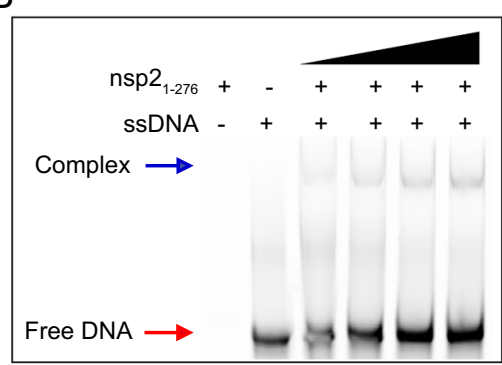

C

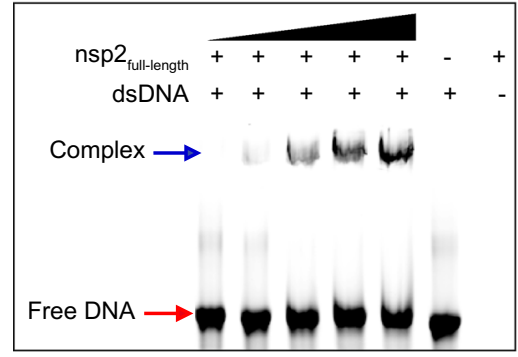

D

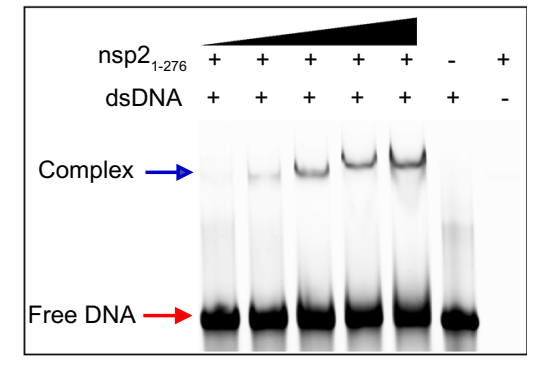

$\mathrm{E}$

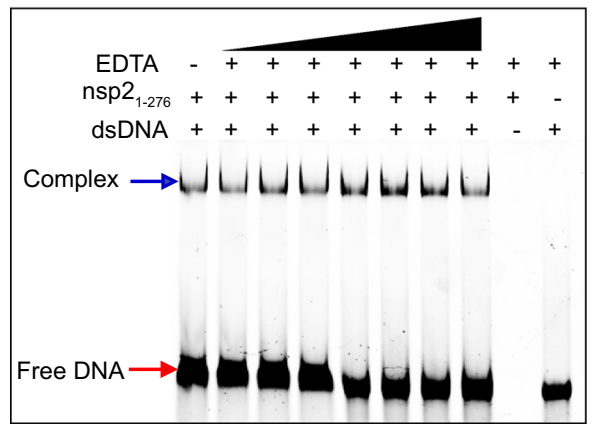

$\mathrm{F}$

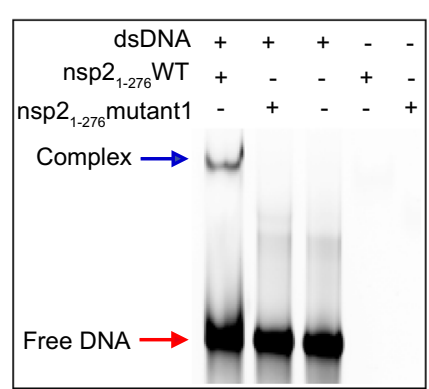

7MSX) at $3.76 \AA$ and $3.15 \AA$, respectively (Gupta et al. 2021). A quick comparison with our structure indicates that the N-terminal $\mathrm{ZnF}$ is similar with a RMSD of 1.3 (Supplementary Fig. S4A). In addition, the RMSD of ZnF1, $\mathrm{ZnF} 2$, and $\mathrm{ZnF} 3$ between these two structures are $0.7 \AA$, $0.5 \AA$, and $1.1 \AA$, respectively (Supplementary Fig. S4BS4D). But there are some differences. Our high-resolution $\mathrm{X}$-ray structure might provide more details, such as the geometry, coordination and distance of ZnFs. A DALI search (Holm and Rosenström 2010) of the overall X-ray nsp2 $2_{1-276}$ structure found no similar structure in the Protein Data Bank (PDB) except for the EM structure of nsp2, indicating that overall nsp2 $2_{1-276}$ structure appeared to be a novel folding type.

Then these three $\mathrm{ZnF}$ structures of nsp2 $2_{1-276}$ caught our attention, and they belonged to $\mathrm{C} 2 \mathrm{H} 2, \mathrm{C} 4$, and $\mathrm{C} 2 \mathrm{HC}$ types, respectively. Structural analysis and mutagenesis results indicated that they did not play important roles in binding nucleic acids. These three $\mathrm{ZnF}$ domains may play other unknown functions. To explore the function, we submitted three $\mathrm{ZnFs}$ to the DALI server to search for structurally similar proteins. $\mathrm{ZnF} 1$ is similar to the protein serine/threonine phosphatase 2C (PDB: 1A6Q) with an RMSD of $2.6 \AA$, which is essential for regulating cellular stress responses in eukaryotes (Das et al. 1996) (Supplementary Fig. S5A). This $\mathrm{ZnF}$ fold is also similar to the eukaryotic DNA transposase (PDB: 2BW3) with an RMSD of $3.0 \AA$ (Hickman et al. 2005) (Supplementary Fig. S5B). These indicated that nsp2 might interact with host genomes to be involved in regulating intracellular signaling pathways. These two structures are similar to $\mathrm{ZnF} 1$ of nsp2, but both lack zinc ions. Furthermore, $\mathrm{ZnF} 2$ is similar to the $50 \mathrm{~S}$ ribosomal protein L44E (PDB: 1S72) with a RMSD of $1.8 \AA$, and four cysteines are highly conserved (Klein et al. 2004) (Supplementary Fig. S5C). Recently, it has been reported that nsp1 and nsp2 prevent the entry of cellular mRNA into ribosomes, and accelerate cellular mRNA degradation to inhibit the synthesis of host protein in cells infected with SARS-CoV-2 (Finkel et al. 2021). This process may be related to the $\mathrm{ZnF} 2$ of nsp2. In addition, $\mathrm{ZnF3}$ is similar to the RNAi polymerase from Neurospora crassa (PDB: $2 \mathrm{~J} 7 \mathrm{~N}$ ) with RMSD of $2.4 \AA$, which is related 
to RNA silencing and regulation of gene expression (Salgado et al. 2006) (Supplementary Fig. S5D). Moreover, cysteines and histidines that coordinated $\mathrm{ZnF} 2$ and $\mathrm{ZnF} 3$ are highly conserved according to sequence alignment of nsp2 ${ }_{1-276}$ between SARS-CoV-2, SARS-CoV, and MERSCoV (Supplementary Fig. S1). This indicated that these two $\mathrm{ZnFs}$ are important in the evolution of viruses.

Previous studies have reported that the deletion of SARS-CoV nsp2 leads to attenuation of viral growth and RNA synthesis. By analysis of protein-protein interactions and involvement of viral proteins in SARS-CoV replication, nsp2 can interact with nsp7, nsp8, and other viral nonstructural proteins (von Brunn et al. 2007; Pan et al. 2008). It is speculated that $\mathrm{nsp} 2$ can assist the formation of replication-transcription complex (RTC) and participate in viral replication and transcription, which needs further study to confirm. The structures of N-terminal nsp2 are the first step to a comprehensive understanding of the structure-function relationship of SARS-CoV-2 nsp2. Our findings, responding to the global pandemic, SARS-CoV-2, are significant to make full use of nsp2 as further research and development of antiviral targets and drug design.

Acknowledgements We would like to thank the staff of beamlines BL17U1 and BL19U2 at the Shanghai Synchrotron Radiation Facility for the excellent technical assistance. We thank Prof. Dr. Bo Zhang for generously providing SARS-CoV-2 nsp2 gene. This work was supported financially by National Key Research and Development Program of China (2018YFE0113100) and National Natural Science Foundation of China (31872713).

Author Contributions JM and ZC designed the experiments. JM, $\mathrm{YC}, \mathrm{WW}$, and ZC carried out the experiments. JM and ZC analyzed the data. JM wrote the paper. JM, YC, and ZC checked and finalized the manuscript. All authors read and approved the final manuscript.

\section{Compliance with Ethical Standards}

Conflict of interest The authors declare that they have no conflict of interest.

Animal and Human Rights Statement This article does not contain any studies with human or animal subjects performed by any of the authors.

Protein Structure Accession Number Final refined coordinates and structure factors have been deposited in the Protein Data Bank (PDB) under accession code 7EXM.

\section{References}

Al-Qaaneh AM, Alshammari T, Aldahhan R, Aldossary H, Alkhalifah ZA, Borgio JF (2021) Genome composition and genetic characterization of SARS-CoV-2. Saudi J Biol Sci 28:1978-1989
Bai Z, Gong Y, Tian X, Cao Y, Liu W, Li J (2020) The Rapid Assessment and Early Warning Models for COVID-19. Virol Sin $35: 272-279$

Clark LK, Green TJ, Petit CM (2021) Structure of Nonstructural Protein 1 from SARS-CoV-2. J Virol 95:e02019-20

Cornillez-Ty CT, Liao L, Yates JR 3rd, Kuhn P, Buchmeier MJ (2009) Severe acute respiratory syndrome coronavirus nonstructural protein 2 interacts with a host protein complex involved in mitochondrial biogenesis and intracellular signaling. J Virol 83:10314-10318

Das AK, Helps NR, Cohen PT, Barford D (1996) Crystal structure of the protein serine/threonine phosphatase $2 \mathrm{C}$ at 2.0 A resolution. EMBO J 15:6798-6809

Emsley P, Lohkamp B, Scott WG, Cowtan K (2010) Features and development of Coot. Acta Crystallogr D Biol Crystallogr 66:486-501

Eom KS, Cheong JS, Lee SJ (2016) Structural Analyses of Zinc Finger Domains for Specific Interactions with DNA. J Microbiol Biotechnol 26:2019-2029

Finkel Y, Gluck A, Nachshon A, Winkler R, Fisher T, Rozman B, Mizrahi O, Lubelsky Y, Zuckerman B, Slobodin B, YahalomRonen Y, Tamir H, Ulitsky I, Israely T, Paran N, Schwartz M, Stern-Ginossar N (2021) SARS-CoV-2 uses a multipronged strategy to impede host protein synthesis. Nature 594:240-245

Graham RL, Sims AC, Brockway SM, Baric RS, Denison MR (2005) The nsp2 replicase proteins of murine hepatitis virus and severe acute respiratory syndrome coronavirus are dispensable for viral replication. J Virol 79:13399-13411

Gupta M, Azumaya CM, Moritz M, Pourmal S, Diallo A, Merz GE, Jang G, Bouhaddou M, Fossati A, Brilot AF, Diwanji D, Hernandez E, Herrera N, Kratochvil HT, Lam VL, Li F, Li Y, Nguyen HC, Nowotny C, Owens TW, Peters JK, Rizo AN, Schulze-Gahmen U, Smith AM, Young ID, Yu Z, Asarnow D, Billesbølle C, Campbell MG, Chen J, Chen K-H, Chio US, Dickinson MS, Doan L, Jin M, Kim K, Li J, Li Y-L, Linossi E, Liu Y, Lo M, Lopez J, Lopez KE, Mancino A, Moss FR, Paul MD, Pawar KI, Pelin A, Pospiech TH, Puchades C, Remesh SG, Safari M, Schaefer K, Sun M, Tabios MC, Thwin AC, Titus EW, Trenker R, Tse E, Tsui TKM, Wang F, Zhang K, Zhang Y, Zhao J, Zhou F, Zhou Y, Zuliani-Alvarez L, Agard DA, Cheng Y, Fraser JS, Jura N, Kortemme T, Manglik A, Southworth DR, Stroud RM, Swaney DL, Krogan NJ, Frost A, Rosenberg OS, Verba KA (2021) CryoEM and AI reveal a structure of SARSCoV-2 Nsp2, a multifunctional protein involved in key host processes. https://doi.org/10.1101/2021.05.10.443524v1

Hickman AB, Perez ZN, Zhou L, Musingarimi P, Ghirlando R, Hinshaw JE, Craig NL, Dyda F (2005) Molecular architecture of a eukaryotic DNA transposase. Nat Struct Mol Biol 12:715-721

Holm L, Rosenström P (2010) Dali server: conservation mapping in 3D. Nucleic Acids Res 38:W545-W549

Justo Arevalo S, Zapata Sifuentes D, Huallpa CJ, Landa Bianchi G, Castillo Chávez A, Garavito-Salini Casas R, Uceda-Campos G, Pineda Chavarria R (2021) Global geographic and temporal analysis of SARS-CoV-2 haplotypes normalized by COVID-19 cases during the pandemic. Front Microbiol 12:612432

Klein DJ, Moore PB, Steitz TA (2004) The roles of ribosomal proteins in the structure assembly, and evolution of the large ribosomal subunit. J Mol Biol 340:141-177

Mateus J, Grifoni A, Tarke A, Sidney J, Ramirez SI, Dan JM, Burger ZC, Rawlings SA, Smith DM, Phillips E, Mallal S, Lammers M, Rubiro P, Quiambao L, Sutherland A, Yu ED, da Silva AR, Greenbaum J, Frazier A, Markmann AJ, Premkumar L, de Silva A, Peters B, Crotty S, Sette A, Weiskopf D (2020) Selective and cross-reactive SARS-CoV-2 $\mathrm{T}$ cell epitopes in unexposed humans. Science 370:89-94 
Murshudov GN, Skubak P, Lebedev AA, Pannu NS, Steiner RA, Nicholls RA, Winn MD, Long F, Vagin AA (2011) REFMAC5 for the refinement of macromolecular crystal structures. Acta Crystallogr D Biol Crystallogr 67:355-367

Nielsen SS, Toft KN, Snakenborg D, Jeppesen MG, Jacobsen JK, Vestergaard B, Kutter JP, Arleth L (2009) BioXTAS RAW, a software program for high-throughput automated small-angle $\mathrm{X}$-ray scattering data reduction and preliminary analysis. J Appl Crystallogr 42:959-964

Ong E, Wong MU, Huffman A, He Y (2020) COVID-19 Coronavirus vaccine design using reverse vaccinology and machine learning. Front Immunol 11:1581

Pan J, Peng X, Gao Y, Li Z, Lu X, Chen Y, Ishaq M, Liu D, Dediego ML, Enjuanes L, Guo D (2008) Genome-wide analysis of protein-protein interactions and involvement of viral proteins in SARS-CoV replication. PLoS ONE 3:e3299

Pelikan M, Hura GL, Hammel M (2009) Structure and flexibility within proteins as identified through small angle X-ray scattering. Gen Physiol Biophys 28:174-189

Salgado PS, Koivunen MR, Makeyev EV, Bamford DH, Stuart DI, Grimes JM (2006) The structure of an RNAi polymerase links RNA silencing and transcription. PLoS Biol 4:e434

Sheldrick GM (2008) A short history of SHELX. Acta Crystallogr A 64:112-122

Shu T, Huang M, Wu D, Ren Y, Zhang X, Han Y, Mu J, Wang R, Qiu Y, Zhang DY, Zhou X (2020) SARS-Coronavirus-2 Nsp13 possesses NTPase and RNA helicase activities that can be inhibited by bismuth salts. Virol Sin 35:321-329

Singh A, Singh RS, Sarma P, Batra G, Joshi R, Kaur H, Sharma AR, Prakash A, Medhi B (2020) A Comprehensive Review of Animal
Models for Coronaviruses: SARS-CoV-2, SARS-CoV, and MERS-CoV. Virol Sin 35:290-304

Sulej AA (2019) Improving selectivity of DNA-RNA binding zinc finger using directed evolution. BMC Res Notes 12:792

von Brunn A, Teepe C, Simpson JC, Pepperkok R, Friedel CC, Zimmer R, Roberts R, Baric R, Haas J (2007) Analysis of intraviral protein-protein interactions of the SARS coronavirus ORFeome. PLoS ONE 2:e459

Wang S, Trilling M, Sutter K, Dittmer U, Lu M, Zheng X, Yang D, Liu J (2020) A Crowned Killer's Résumé: Genome, Structure, Receptors, and Origin of SARS-CoV-2. Virol Sin 35:673-684

Yip CC, Ho CC, Chan JF, To KK, Chan HS, Wong SC, Leung KH, Fung AY, Ng AC, Zou Z, Tam AR, Chung TW, Chan KH, Hung IF, Cheng VC, Tsang OT, Tsui SKW, Yuen KY (2020) Development of a novel, genome subtraction-derived, SARSCoV-2-SPECIFIC COVID-19-nsp2 Real-Time RT-PCR assay and its evaluation using clinical specimens. Int $\mathrm{J}$ Mol Sci 21:2574

Yu F, Wang Q, Li M, Zhou H, Liu K, Zhang K, Wang Z, Xu Q, Xu C, Pan Q, He J (2019) Aquarium: an automatic data-processing and experiment information management system for biological macromolecular crystallography beamlines. J Appl Cryst $52: 472-477$

Zhao J, Zhai X, Zhou J (2020) Snapshot of the evolution and mutation patterns of SARS-CoV-2. bioRxiv.https://doi.org/10.1101/2020. $07.04 .187435 \mathrm{v} 1$ 